\title{
Intercultural Education - Obstacles and Prospects in Greece
}

\author{
Amvrosiadis Emmanouil \\ University of Aegean, Greece
}

\begin{abstract}
The last decade, in addition to the economic crisis, has brought a huge number of immigrants to Greece. As a result, there were several difficulties but also perspectives on issues related to intercultural education, which had been neglected for many years. This paper examines the factors that affect the present and future of intercultural education in Greece. These factors are considered at different levels. First, at the institutional level, the legislation and regulations are analyzed as well as the other measures implemented to ensure adequate and effective education for refugees and migrants. Second, at an ideological level, issues related to the denial of diversity and effective or ineffective management as it may be reflected in the curricula are examined and whether they contribute to and reproduce stereotypes and ethnocentric ideologies. Third, practices related to the acceptance of diversity and to what extent they have been achieved. Finally, reference is made to actions that promote intercultural education as well as to voluntary actions of local authorities and educational institutions aimed at supporting refugees and immigrants.
\end{abstract}

Keywords: diversity; education; intercultural; legislation; refugees. 